\title{
La Nobleza Tarasca: poder político y conflictos en el Michoacán colonial
}

\author{
Carlos Salvador Paredes Martínez
}

Centro de Investigaciones y Estudios Superiores en Antropología Social, (CIESAS), México

En este trabajo se observan las condiciones que propiciaron la introducción de las instituciones de gobierno indígena en Michoacán, el surgimiento de los nuevos actores políticos y el desplazamiento de la nobleza heredera de los linajes gobernantes en la época prehispánica. Se presentan algunos casos en los que se muestran las nuevas formas de actuación en defensa de los derechos que la legislación española permitía a los nuevos vasallos indígenas y los discursos y argumentos que utilizarán los actores políticos para conseguir sus privilegios y derechos.

PALABRAS ClaVE: Tarascos, pueblos conquistados, gobierno indígena.

In this work are observed the conditions that caused the introduction of the institutions of indigenous government, the sprouting of the new political actors and the displacement of the inheriting nobility of the governing lineages at the pre-Hispanic time. Some cases in that appear are the new forms of performance in defense of the rights that the spanish legislation allowed to the new indigenous vassals and the speeches and arguments that the political actors will use to obtain to their privileges and rights.

KeYwords: Tarascos, Conquered Towns, Indigenous Government.

La conquista de Michoacán por parte de los españoles trajo consigo cambios drásticos en las formas de gobierno entre las poblaciones indígenas, así como también fue ocasión para el surgimiento de nuevos grupos de poder local y regional, poderes que anteriormente estaban fuertemente controlados por el cazonci (noble gobernante) y la familia real del linaje uacusecha en la época prehispánica. Según su cosmovisión y sus propias tradiciones ancestrales, se consideraban descendientes de las águilas y este dignatario personificaba al dios curicaueri en la tierra, representado por el sol y el fuego, quién ordenó cómo había de ser rey, conquistar toda la tierra y formar un solo señorío en "esta provincia de Mechuacán". ${ }^{1}$ La con-

1 Relación de Michoacán, Escobar Olmedo, Armando Mauricio (Coordinador general de la obra), Patrimonio Nacional-H. Ayuntamiento de Morelia-Testimonio Compañía Editorial, Madrid, 2001, volumen de estudios, pág. 250. 
quista española en 1522 es, así, un momento coyuntural de gran trascendencia para este pueblo, por medio del cual podemos observar no sólo el complejo proceso de institucionalización de los sistemas y formas de gobierno introducidos por la metrópoli española, sino que, además, nos permite contemplar la aparición de otros grupos de poder en el interior del antiguo señorío tarasco, así como observar los conflictos y los nuevos discursos y actuaciones en busca de la legitimación del poder en un nuevo contexto colonial. De esta manera el presente trabajo aborda, en términos generales, la aparición de nuevos sectores de la sociedad indígena tarasca, la conflictividad social que le es propia y las consecuencias más importantes del establecimiento de los sistemas de gobierno introducidos por la Corona española en el Michoacán colonial, durante las etapas tempranas.

Una primera consideración importante es que desde la primera década de la conquista y apenas unos años después de la caída de MéxicoTenochtitlan, la presencia española en estas tierras era ya determinante en el devenir histórico de sus pueblos autóctonos. Se había dado la franca rendición del señorío por parte del cazonci ante el propio Hernán Cortés hacia 1524; se otorgaron una gran cantidad de pueblos indígenas bajo el régimen de la encomienda, en base a un informe de Antonio de Carvajal redactado in situ entre 1523-1524 y regularizadas las tasaciones de tributos de los mismos en 1528; se inició la evangelización a cargo de la orden franciscana desde mediados de esta década, previo el bautizo del propio cazonci y posteriormente "bautizáronse todos", así como se envió a unos quince niños nobles a la ciudad de México para su evangelización, a cargo de los frailes de esa misma orden desde estos años; y finalmente, una visita del oidor de la Segunda Audiencia de la Nueva España, el licenciado Vasco de Quiroga a Michoacán en el año de 1533, marcaría el inicio de la presencia de un hombre de fuerte influjo y personalidad, que dejaría una honda huella en el pueblo purépecha que aún subsiste hasta la actualidad. ${ }^{2}$

A lo anterior hay que añadir los factores histórico-geográficos no menos importantes, relativos a la ubicación del territorio que nos ocupa en el centro-occidente de Mesoamérica, limítrofe con los grupos hostiles de la gran chichimeca y en el septentrión novohispano, hacia donde materialmente se volcó el interés de los exploradores, gambusinos, buscadores de fama y riquezas, visitadores y hasta del mismo virrey Antonio de Mendoza,

2 El mejor estudio sobre la conquista de Michoacán continúa siendo: Warren, Benedict: $L a$ conquista de Michoacán 1521-1530, Agustín García Alcaraz (traducción), Fimax Publicistas, Morelia, 1977 (segunda edición, 1989); La Relación de Michoacán..., pág. 349 
desde la década de 1540 y principalmente en la segunda mitad del siglo $\mathrm{XVI}$ en donde, por el descubrimiento de ricas minas de oro y plata y los vastos territorios por conocer, dirigieron sus pasos y sus esfuerzos por colonizar estas tierras. En esta nueva empresa, la población tarasca sería la mejor aliada de los españoles, por su cercanía a estas tierras, por haber aceptado desde sus inicios la sujeción a la Corona y por haberse cristianizado igualmente en fechas tempranas. Es decir, la colaboración de estos pueblos no sólo sería en el aspecto militar, guerrero y colonizador, sino además acompañando a los religiosos franciscanos y agustinos en su odisea evangelizadora al centro y norte de la Nueva España, utilizando precisamente a los tarascos catequizados, como ejemplo y vehículos de transmisión de las formas de vida sedentaria y cristiana a los diversos grupos de pobladores indios que se negaban a aceptar el catolicismo en el extenso territorio de la gran chichimeca. Éste sería tan sólo el inicio también de una relación laboral de los pueblos tarascos con el llamado Bajío y reales mineros del norte, que se prolongaría por buena parte de la época colonial, bajo distintos sistemas de trabajo, así como proveedores de alimentos y materias primas, propias de las tierras caliente y fría de la rica y variable geografía michoacana.

\section{En búsqueda de las instituciones de gobierno}

Una de las más importantes obras de trascendencia, atribuidas a Vasco de Quiroga, convertido en primer obispo de Michoacán en 1538, es la introducción aquí de la institución del hospital, entendido no sólo como un lugar de asistencia al enfermo, huérfanos y desvalidos, sino además como un modelo de sociedad, muy semejante a la utopía de Tomás Moro, que se enmarcaba dentro de los planes de los humanistas y pensadores europeos del siglo XVI. En el caso de Michoacán, esta institución se propagó ampliamente en los pueblos de indios, quienes la acogieron y adoptaron sus nuevas formas de organización social y política, ya que en las ordenanzas del propio obispo sobre el funcionamiento de los hospitales se incluía la existencia de espacios específicos para "que se congregaran los miembros de los ayuntamientos indígenas", es decir, que bajo este modelo de PuebloHospital se preveía no sólo la organización religiosa y asistencial mutua entre sus pobladores, sino además la adopción de la institución de los Ayuntamientos a la manera de los Cabildos españoles, proyecto que coin- 
cidía o al menos fortalecía los planes de la Corona y del virrey Antonio de Mendoza, en el mismo sentido de introducir en los pueblos de indios las repúblicas de indios y sus Cabildos, como forma de gobernarse a sí mismos, evidentemente bajo la tutela de las autoridades españolas locales y virreinales. ${ }^{3}$

Estos y otros autores han constatado, basándose en la documentación de la época, que efectivamente la fundación y establecimiento de hospitales en los pueblos de indios de Michoacán se propagaron ampliamente, pudiendo observarse la existencia de éstos desde el siglo XVI, así como la vigencia de los Cabildos indios, como el de la ciudad de Pátzcuaro, en funciones desde el año de 1545, sin duda el centro político y hegemónico más importante desde el punto de vista del proyecto quiroguiano y de la nobleza tarasca descendiente del linaje uacusecha prehispánico. En muchas otras poblaciones de Michoacán encontramos la vigencia de esta estructura de gobierno a través de las elecciones de los integrantes de Cabildos, la fijación de los sueldos de los funcionarios, los nombramientos de determinados cargos, las presiones de grupos por favorecer a tal o cual gobernador, etc., lo que nos indica el funcionamiento de la república de indios como figura jurídica en la legislación indiana, la institución de los Cabildos indígenas con sus cuerpos de gobierno a la manera de los Cabildos españoles de villas y ciudades, así como la utilización por parte de los indios de los recursos de acudir a las autoridades españolas, incluyendo al propio virrey en la capital del virreinato, para apelar una decisión, detener abusos o fraudes en las elecciones, etc., mostrando con ello la adopción de las formas de gobernarse y sacar así el mejor partido a través de la casuística legislación española. Paralelamente, la documentación de la época nos menciona que el primer virrey, Don Antonio de Mendoza, se encargó de hacer nombramientos de gobernadores, alcaldes, alguaciles y jueces de justicia en los pueblos de indios de la Nueva España, como una forma de establecer la institucionalización del gobierno en estos pueblos y de estabilizar el gobierno

3 Sobre Vasco de Quiroga y su obra hospitalaria existe una amplia bibliografía, sólo cito unas cuantas obras de importancia: Zavala, Silvio: La "utopía" de Tomás Moro en la Nueva España y otros estudios, Antigua Librería de Robredo, México, 1937; Muriel, Josefina: Hospitales de la Nueva España, 2 volúmenes, Instituto de Historia, México, 1956; Warren, J. Benedict: Vasco de Quiroga y sus hospitales pueblo de Santa Fe, Universidad Michoacana, Morelia, 1977; Serrano Gassent, Paz: Vasco de Quiroga.Utopía y derecho en la conquista de América, Fondo de Cultura Económica de España-Universidad Nacional de Educación a Distancia, Madrid, 2001; Warren, Benedict y Sánchez del Olmo, Sara: Las guatáperas hospitalitos y capillas de Michoacán, Rotodiseño y color, México, 2007. 
en general, de una entidad que años antes se presentaba confusa y hasta caótica, particularmente en Michoacán. ${ }^{4}$

El arraigo e importancia que los tarascos le dieron a esta institución del hospital, así como a la de la cofradía de nuestra señora de la Concepción, igualmente de inspiración quiroguiana, se observa no sólo en su antiguo territorio, sino también en los lugares lejanos de la Nueva España a donde, por razones de trabajo, tuvieron que migrar y establecerse, de manera que se encuentra, por ejemplo, un hospital de tarascos en las inmediaciones de las minas de Taxco hacia 1564, donde debían de acudir a trabajar y proveer de carbón, madera y alimentos a estos centros de laboreo, así como también observamos la existencia de estas instituciones hospitalarias y de cofradías en zonas a las que llegaron tarascos migrantes, como Irapuato, Guanajuato, Zacatecas, San Luis Potosí y Aguascalientes desde el siglo XVI.

\section{Los actores políticos y los conflictos}

Ahora bien, dentro de estos nuevos escenarios institucionales y esquemas del quehacer político, es donde se desarrollarán los actores políticos, quienes, en una nueva gama de categorías sociales, pugnarán por hacer valer sus privilegios y derechos que les otorgaba la legislación española, mientras que sectores que anteriormente tenían vedada cualquier expresión política o de participación en los gobiernos locales, surgirán a la vida pública y ocuparán puestos de gobierno u otras actividades requeridas por el Cabildo constituido, en la medida en que la nobleza real tarasca disminuía al punto de su extinción en la línea legítima en 1577 y de la línea ilegítima hacia 1695, con la muerte de don Constantino Bravo Huitziméngari. ${ }^{6}$ Por

4 López Sarrelangue, Delfina Esmeralda: La nobleza indígena de Pátzcuaro en la época virreinal, Instituto de Investigaciones Históricas-Universidad Nacional Autónoma de México, México, 1965; Paredes Martínez, Carlos (editor): "Y por mí visto...” Mandamientos, ordenanzas, licencias y otras disposiciones virreinales sobre Michoacán en el siglo XVI, Víctor Cárdenas Morales, Iraís Piñón Flores, Trinidad Pulido, Centro de Investigaciones y Estudios Superiores en Antropología SocialUniversidad Michoacana de San Nicolás de Hidalgo, México, 1994; Paredes Martínez, Carlos: "Instituciones coloniales en poblaciones tarascas. Introducción, adaptación y funciones" en Paredes Martínez, Carlos y Terán, Marta (Coords.): Autoridad y gobierno indígena en Michoacán. Ensayos a través de su historia, volumen 1, El Colegio de Michoacán-Centro de Investigaciones y Estudios Superiores en Antropología Social -Instituto Nacional de Antropología e Historia- Universidad Michoacana de San Nicolás de Hidalgo, México, 2003, págs. 140-141.

5 Archivo General de la Nación, tierras, 18, 1. ${ }^{a}$ parte, 3; Archivo Histórico del Estado de Zacatecas, libro $1 .^{\circ}$ de Cabildo.

6 López Sarrelangue: La nobleza indígena..., págs. 181-205. 
otro lado, y como sucedió en otros ámbitos de la Nueva España, el sector social noble, fuera de la familia real uacusecha, con alguna presencia en los gobiernos locales y con privilegios en la exención de los tributos y obligaciones laborales, igualmente fue perdiendo estos privilegios, en la medida en que las exigencias de las autoridades y encomenderos españoles eran mayores, ocurriendo el fenómeno de la "macehualización" de la población indígena en general, a fin de igualarla en términos sociales, obviando sus diferencias inclusive linguísticas y predominando así la denominación generalizada de "indios".

Seguramente uno de los primeros conflictos en el interior de la nobleza tarasca, al momento del arribo español a Michoacán, sea el de la decisión en torno precisamente al recibimiento de los conquistadores, después de los trágicos acontecimientos de la conquista de Tenochtitlan el 13 de agosto de 1521. De igual magnitud e importancia lo fue el hecho de la sucesión en la gobernación del señorío tarasco, cuando el 14 de febrero de 1530, Nuño de Guzmán, presidente de la primera Audiencia, realiza un juicio sumario, acusando al cazonci de haber sacrificado algunos españoles y continuar con los ritos paganos. Aún cuando ambos acontecimientos son distantes casi nueve años uno de otro y entre ellos sucedieron múltiples hechos históricos de importancia, los he relacionado aquí en razón de que, en la historiografía de la época, los dos sucesos están permeados por la narrativa "oficial" de La Relación de Michoacán, de don Pedro Cuiniarángari, un personaje un tanto oscuro, "hermano adoptivo del cazonci", caracterizado por Rodrigo Martínez como un hombre que se "coló" en la historia, quién asumió la sucesión del gobierno de lo que fue el señorío tarasco, tras la ejecución y muerte del máximo dirigente y así en dicha fuente aparece como el conciliador, el apaciguador de las posiciones radicales que se oponían a toda costa a dar la bienvenida a los españoles y quién desempeñó un papel fundamental en la estabilización del convulsionado territorio entre 1530 y 1543 , el año de su muerte. ${ }^{7}$ De esta manera la fuente fundamental de la etnohistoria tarasca está no sólo tamizada por la predominancia de la voz y la interpretación de personajes como don Pedro, sino también, como lo han dicho otros autores, se trata de una fuente "lagocéntrica" en la que el señorío uacusecha sobresale como el único y más importante de Michoacán, subestimando a otros caci-

7 Martínez Baracs, Rodrigo: Convivencia y utopía. El gobierno indio y español de la "ciudad de Mechuacan”1521-1580, Instituto Nacional de Antropología e Historia-Fondo de Cultura Económica, México, 2005, págs. 119-134. 
cazgos y entidades étnico-políticas que pudieron existir dentro del mismo territorio. ${ }^{8}$

Fuera de una manera $u$ otra, es evidente la preexistencia desde la época prehispánica de fuertes conflictos en el interior de la propia familia real y entre la nobleza gobernante, así como la abierta disidencia de personajes como Timas, los conflictos regionales en contra del grupo hegemónico por ejemplo en la sierra, con rivalidades entre pueblos limítrofes o los permanentes acosos en las fronteras del señorío, al menos por sus tres costados del territorio, todo lo cual vino a supeditarse a los nuevos designios de los españoles a partir de la rendición del señorío en 1524 y al gobierno "provincial" del sucesor del cazonci, don Pedro Cuiniarángari, en esta primera etapa de la historia colonial de Michoacán.

En una siguiente etapa de reacomodos, aún cuando de mayor estabilización de las fuerzas políticas indígenas de Michoacán, podríamos circunscribirla al período de 1543 a 1562, en el que tras el breve gobierno de dos años del sucesor legítimo del señorío don Francisco Tariácuri, su hermano, don Antonio Huitziméngari, asumió el gobierno, prolongándolo hasta la última fecha señalada, ocurriendo en este período los más trascendentales cambios en el gobierno indígena de carácter provincial y local. Tienen lugar, entre otros hechos destacables, el reconocimiento por parte de la Corona española de los verdaderos y legítimos descendientes del último soberano del señorío tarasco, el cazonci y sus sucesores, otorgándole la corona española a don Antonio, una renta perpetua por 500 pesos y el reconocimiento de su nobleza; al mismo tiempo, y como se decía antes, el reparto de pueblos de indios bajo el régimen de encomiendas a particulares españoles y el establecimiento de Alcaldías y Corregimientos en múltiples pueblos de Michoacán, son el factor determinante en la atomización del poder político, antes fuertemente centralizado en la persona del cazonci, contribuyendo sin lugar a dudas estos hechos a una nueva organización de la geografía política del antiguo señorío.

Esta reorganización territorial y política del señorío debió empezar por el corazón mismo de su antiguo dominio, es decir la cuenca del lago de Pátzcuaro, con los siguientes acontecimientos determinantes: el cambio de capital ordenado por el obispo Vasco de Quiroga de Tzintzuntzan a Pátzcuaro en 1538, el pleito entre el mismo obispo con el encomendero Juan Infante por los llamados "Barrios de la Laguna", entre 1539 y 1554,

8 Roskamp, Hans: La historiografía indígena de Michoacán. El lienzo de Jucutácato y los títulos de Carapan, Leiden University -Research School CNWS, Leiden, 1998. 
que no eran otros que los pueblos situados en la parte poniente del propio lago, vitales para la subsistencia de la nueva capital y sede del obispado; la creación de una "Nueva Ciudad de Michoacán" por parte del virrey Antonio de Mendoza en 1541, que vendría a rivalizar con el antiguo epicentro lacustre, convirtiéndose a partir de 1577-1580 en sede de los poderes civiles y religiosos del Obispado de Michoacán, cambiando su nombre por el de Valladolid (hoy Morelia, capital del estado de Michoacán) y, por si fuera poco, a finales de este siglo, la separación como república independiente de Pátzcuaro de la propia ciudad de Tzintzuntzan, con todos sus pueblos sujetos, tras una prolongada lucha legal por el reconocimiento de la antigua capital del señorío, con el nombramiento de ciudad y con su escudo de armas, así como con el conjunto de atributos de una república de indios independiente, como el cobro de tributos de sus sujetos, el poder hacer elecciones de sus autoridades, la administración de sus bienes y recursos, etc.

Todos estos acontecimientos sin duda provocaron la disminución cada vez mayor del poder de los sucesores del cazonci, representados ahora, y al menos desde 1545, en la figura de la república de indios de Pátzcuaro y en su Cabildo indígena. Este proceso de fragmentación política y disminución de los alcances del poder político, del gobierno de la nobleza y del mismo cuerpo de Cabildo de Pátzcuaro, pudo ser un ejemplo de lo sucedido en otros muchos pueblos de indios en Michoacán, acotando cada vez más sus territorios y sus poderes de decisión, coincidiendo además este proceso con la política de congregación de pueblos en espacios concentrados y que en Michoacán se presentó, desde estos años, con las experiencias colonizadoras en que derivó el conflicto entre el obispo Vasco de Quiroga y el virrey Antonio de Mendoza por la sede episcopal, concretadas en la reunión de pueblos de indios de muy diversas partes, para consolidar las ciudades de Pátzcuaro y Valladolid respectivamente. Otras congregaciones debieron hacerse en diversas regiones y pueblos de indios de Michoacán, antes de volver a ellas, como una política generalizada en todos los dominios españoles, a finales del siglo XVI. ${ }^{9}$

Por su parte, la antigua estructura jerárquica de gobierno del señorío tarasco, detalladamente representada en dos láminas de La Relación de

9 Paredes Martínez, Carlos: "Gobierno y pueblos de indios en Michoacán en el siglo XVI” en Paredes Martínez, Carlos (Director general): Arquitectura y espacio social en poblaciones purépechas de la época colonial, Universidad Michoacana de San Nicolás de Hidalgo-Universidad Keio-Centro de Investigaciones y Estudios Superiores en Antropología Social, Morelia, 1998, pág. 21-45. 
Michoacán y desde luego en toda la obra, ${ }^{10}$ sin duda fue un antecedente importante en las nuevas formas del gobierno colonial, excluyendo desde luego a los antiguos sacerdotes y sus prácticas de la religión "pagana", así como ciertas prácticas de distribución y redistribución de mantas, alimentos y otros bienes que el cazonci y la elite gobernante almacenaban en las "trojes estatales" y que mediante esta práctica, de alguna forma retribuían a sus súbditos y contribuían a legitimar su poder. Una treintena de estos cargos, funciones y oficios especializados pudieron haber desaparecido completamente, dada la nueva estructura de gobierno y la ausencia de una centralidad de este en Michoacán, sin embargo otros cargos más subsistieron o se adaptaron a las nuevas funciones del Cabildo, el cobro de tributos por parte de los encomenderos o los servicios laborales, en los que los destinos a las minas van a tener una mayor demanda y para lo cual los tarascos igualmente fueron una fuerza de trabajo importante. Persistieron, en cambio, los oficiales de hacer casas, los cacari o canteros y pedreros, los uaruri o diputados sobre todos los pescadores de red, quién "...todavía tiene esta costumbre"; "déstos hay todavía muchos", esto es, hacia 1540, en que se redactó esta obra. Los cargos de gobernador y otros integrantes del Cabildo indígena debieron recaer en la antigua nobleza local, en los inicios sucediendo los hijos como en la época prehispánica, según ocurrió en Ucareo en 1551, y otras veces por nombramientos directos del virrey Mendoza y después haciéndose valer la autoridad de los Cabildos constituidos en cada pueblo cabecera, por medio de las elecciones por parte de un selecto grupo de principales. ${ }^{11}$

De la misma manera habría que considerar al respecto en estas ocupaciones a los antiguos sacerdotes y carariecha (los pintores de códices), quienes, debido a sus conocimientos de las expresiones pictóricas, del tiempo y de las artes, suprimiendo sus antiguas prácticas y ceremonias religiosas, debieron ser requeridos en los nuevos puestos de Cabildo como escribanos, traductores e informantes de los religiosos dedicados al rescate de las lenguas y la historia, así como agrimensores en los nuevos repartos y deslindes de la tierra, entre muchas otras ocupaciones, requeridas en la construcción de los gobiernos de las repúblicas de indios. En el caso específico del cargo del ocambecha - los antiguos cobradores de tributos, encargados de contar y reunir a los trabajadores para las obras públicas en

10 Relación de Michoacán, Armando Mauricio Escobar Olmedo (Coordinador general de la obra), volumen facsimilar, láminas XXVIII y XXIX.

11 Paredes Martínez, Carlos (Ed.): “Y por mí visto..., documentos 41 y 56; Real Academia de la Historia, Colección Juan Bautista Muñoz, 9-4849, foja 111v. 
la época prehispánica—, sabemos que continuaron con esta labor recaudatoria del tributo, así como en la estructura jerárquica de los Cabildos, cumpliendo su labor, ahora con 25 casas a su cargo y uno general que reunía el tributo de todos ellos, al menos hacia 1541, en la cuenca lacustre de Pátzcuaro. Si bien es cierto que para el año 1586 aún persistía el cargo de los ocambetis y en épocas posteriores aparece recurrentemente en los registros de cuentas y otros documentos de las comunidades, sin embargo es muy posible que, a medida que se consolidaba el Cabildo indígena como institución básica de gobierno local, con todas las funciones y cargos conocidos, las tareas se hayan redistribuido al modo de los Cabildos españoles, quedando la responsabilidad última al gobernador de cada pueblo.

En este contexto y como una muestra ilustrativa del nuevo quehacer político entre las poblaciones indígenas de Michoacán, destacamos tres casos. El primero de ellos se refiere a los abusos y excesos de un español de la tierra caliente del oriente de Michoacán, de nombre Gonzalo Ruiz, encomendero de Cutzio y Huetamo, quién, siendo regidor de la ciudad de México, pretendía despojar de sus tierras a los indios y ordenó arrestar al alguacil indio de Coyuca, quitándole la vara, encadenándolo del cuello y llevándolo preso a dicha ciudad. Además, había dado de palos al cacique don Juan hasta matarlo. Ante estos hechos sucedidos en la década de 1540, los indios y sus autoridades de estos pueblos no se conforman sólo con protestar, sino que armaron toda una argumentación en dos códices mixtos (los códices de Cutzio y Huetamo), presentando las tasaciones de tributos a los que estaban sujetos y negándose a pagar de más, así como acusando a dicho encomendero de los abusos y demás tropelías que había cometido en su contra. Se dice: “... ha hecho ciertas palabras en ofensa de dios nuestro señor y de su majestad diciendo, 'que le ha de hacer dios y el rey', renegando de su creador y maldiciendo el bautismo y crisma y otras blasfemias". En otra fuente posterior, se dice que la gente de este pueblo era de lo más pulida y bien tratada que hay en esta provincia, por lo que con los abusos que cometió su encomendero, el pueblo "está escandalizado". De esta manera presentaron sus testimonios pictográficos y documentos fiscales y acudieron ante el mismo virrey para denunciar los abusos. ${ }^{12}$

12 Paredes Martínez, Carlos: "Los códices de Cutzio y Arao: reinterpretación y notas etnohistóricas de la tierra caliente michoacana" en Rueda Smithers, Salvador, Vega, Constanza y Martínez, Rodrigo (Eds.): Códices y documentos sobre México, Segundo Simposio, volumen II, Instituto Nacional de Antropología e Historia-Consejo Nacional para la Cultura y las Artes, México, 1997, págs. 407-411; Roskamp, Hans: Los códices de Cutzio y Huetamo. Encomienda y tributo en la tierra caliente de Michoacán, siglo XVI, El Colegio de Michoacán-El Colegio Mexiquense, México, 2003. 
El siguiente ejemplo se refiere a la denuncia presentada en contra, no del encomendero, sino acusando al propio cacique del pueblo de Zinapécuaro, al norte del actual estado de Michoacán, por abusos también en el cobro de tributos, excesos en los servicios laborales, la falta del pago correspondiente, azotes y castigos corporales, el despojo de tierras y hasta abusos de carácter sexual en contra de la esposa de uno de los denunciantes, es decir una cantidad de delitos acumulados en un total de 500, en contra del cacique Alonso Huapean. En este caso igualmente presentados ante las autoridades locales españolas, mediante un larguísimo expediente con escritura en purépecha, castellano y desde luego pictografías ilustrando dichos abusos, esta vez presentados por los indios principales y tributarios de la cabecera y los pueblos sujetos. El resultado de estas denuncias no lo conocemos, sin embargo la sola denuncia y sus gestiones ante las autoridades locales y virreinales hacia 1560, por parte de los nuevos actores políticos de pueblos y sujetos a Zinapécuaro, debió ser un golpe inusitado contra un cacique que, como muchos otros, provenía de un poder constituido desde la época prehispánica, sancionado y en funciones a partir del ungimiento por parte del cazonci. ${ }^{13}$

El tercer caso aquí reseñado ha sido citado antes brevemente, me refiero al cambio de capital de Tzintzuntzan (la prehispánica) a Pátzcuaro, llevado a cabo por el obispo Quiroga en 1538 y la división que provocó dentro de la misma nobleza tarasca, al negarse una parte al traslado de la capitalidad. El hecho no fue menor, si consideramos que esta nobleza disidente persistió a lo largo del XVI en su objetivo de recuperar la calidad de ciudad y la independencia de Pátzcuaro, lográndolo al final de este siglo, así como también en épocas posteriores sus pobladores tzintzuntzeños dieron amplias muestras de su autonomía, al decir de Felipe Castro:

"La defensa de la autonomía de Tzintzuntzan es una historia que merece atención y comentarios. Es, para empezar, constante; los incidentes de los que tenemos documentación se distribuyen a lo largo de varios siglos de vida colonial, de manera que es claro que no se trata de incidentes circunstanciales. Por el contrario, tal parece que cada generación retomaba la lucha por la autonomía en el lugar que la habían dejado sus mayores. Este fue el tema central y más duradero de la vida política local.”14

13 López Sarrelangue, Delfina Esmeralda: La nobleza indígena..., pág. 98; Zbirkova, Simona: Estudio del códice Huapean. Gobierno y justicia en Zinapécuaro, Michoacán siglo XVI, Tesis Maestría en Antropología Social, Centro de Investigaciones y Estudios Superiores en Antropología Social, 1997.

14 Castro Gutiérrez, Felipe: "Tzintzuntzan: la autonomía indígena y el orden político en la Nueva España" en, Paredes Martínez, Carlos y Terán, Marta (Coords.): Autoridad y gobierno indígena en Michoacán, págs. 293-294. 
Sin duda estos ejemplos nos muestran las formas de adaptación de los nuevos actores políticos a los cauces y laberintos burocráticos, a los que había que acudir para defenderse de los abusos y las nuevas formas de luchar por conseguir privilegios y derechos, utilizando no sólo los documentos y trámites que establecía la legislación española, sino además acudiendo a los argumentos y discursos de la propia conquista y evangelización cristiana. Como súbditos, los tarascos habían aprendido a ser buenos cristianos y vasallos, de manera que, mediante la propia legislación novohispana establecida, harían valer sus derechos y privilegios, como se verá en seguida.

\section{El discurso y los motivos de los nuevos vasallos}

Como se ha visto en el caso de los quejosos indios de Cutzio y Huetamo, ellos acusaban al encomendero de renegado por no seguir las leyes de Dios ni de su rey, sin embargo en el caso de la nobleza descendiente del linaje real uacusecha, la argumentación en su favor será evidentemente mucho más elaborada y desde luego usando su experiencia como colaboradores en la conquista de la gran chichimeca y otros servicios prestados al rey; desgraciadamente no son muy abundantes estos testimonios, pero sí muy significativos.

El mejor ejemplo en este sentido lo tenemos en la documentación que surgió a iniciativa de los descendientes de esta nobleza, empezando por la imagen que presentó de sí mismo don Pedro Cuiniarángari ante el fraile compilador de La Relación de Michoacán, Jerónimo de Alcalá, y del cual ya se ha expuesto antes; sin embargo otros testimonios documentales y pictográficos nos dan muestra de estos discursos que es necesario tomar en cuenta. En el caso de don Antonio Huitziméngari, él destacará no sólo su participación directa en el combate contra los grupos hostiles en la gran chichimeca, sino que además resaltará su propio ejemplo formativo y en la hispanización de las formas de vida. Aprendió las lenguas clásicas como el latín y el griego, vestía a la usanza española; daba testimonios orales y escritos a sus súbditos y a las autoridades españolas en torno a la imagen de un pasado glorioso de un gran señorío; desde luego resaltaba su aceptación de la conquista española, la adopción del cristianismo y de la trascendencia que con su ejemplo y obra dejó al mundo indígena e hispano. El nombramiento de capitán a favor de don Antonio, en el combate a los chi- 
chimecas en noviembre de 1551, así como la compañía expresa de "algunos principales" y hasta mil combatientes tarascos, fue sin duda un elemento fundamental en las nuevas formas de reconocimiento de las que supo sacar provecho el descendiente del antiguo cazonci, así como también fue ejemplo para que otros principales y nobles tarascos asumieran cargos de combate en esta guerra y desde luego buscaran ocupar los puestos de gobierno como gobernadores de los pueblos u otras funciones dentro del esquema del Cabildo de indios.

En un testimonio de don Antonio que buscaba justamente legitimar su ascendencia noble y su derecho a percibir rentas por parte de la Corona, éste argumentaba que su abuelo, el cazonci, era rey y legítimo señor de toda la tierra y "la provincia tarasca", que este territorio comprendía hasta "más delante de Culiacán" al noroeste de la Nueva España, lo cual evidentemente es una exageración, sin embargo este testimonio, pudo ser el referente para la realización de un mapa que publicó posteriormente el cronista Pablo Beaumont, titulado por él: "Plano iconográfico del reyno de Michoacán y estados del gran Caltzontzin", en el que se muestra esta gran extensión del territorio occidental de la Nueva España, sus límites políticos y una gran cantidad de topónimos y accidentes geográficos ${ }^{15}$ que la transmisión de la sucesión en el gobierno del señorío le venía de padre a hijo desde hacía 700 años y que por lo tanto no era por "elección de gentes". A continuación se expresa el argumento principal para la justificación de su petición: se dice que el cazonci se entregó de paz, que se bautizó él y todos sus vasallos, acusó de traición al presidente de la primera Audiencia Nuño de Guzmán, por el hecho de que, a pesar de que su padre le dio los tesoros de la familia, lo mandó ejecutar para quedarse con el dinero y así que nadie supiera de la entrega; y finalmente hace un contraste con los mexicanos del valle de México, diciendo que de todos era conocido que el señorío tarasco era muy fuerte, pujante en armas y que sin embargo recibió en paz a los españoles y aceptó el catolicismo, cosa que no hicieron los mexicanos, de ahí don Antonio posiciona a la provincia de Michoacán como la "más principal" por su lealtad a los conquistadores. Finalmente habla en torno a la formación educativa e "hispana" del mismo, como ya se ha indicado, en donde se llega a decir que es tan español "como si fuese nacido en España". ${ }^{16}$

15 Beaumont, Pablo: Crónica de Michoacán, [escrita hacia 1778-1780], 3 volúmenes, Archivo General de la Nación, México, 1932, mapa 4.

16 Archivo General de Indias, Patronato Real, 60, Número 2, Ramo 3. Información de don Antonio Hitziméngari de 1553. 
Por su parte don Constantino Huitziméngari, hijo ilegítimo de don Antonio, igualmente argumentando en su favor para solicitar una renta anual, se refería a la rendición del señorío tarasco a los españoles, a la participación de don Antonio en la colonización de tres villas de españoles, una de las cuales pudo ser San Felipe, al norte del actual estado de Guanajuato, así como se refiere a los términos del señorío, más reales que los señalados por su padre, en el que incluye a Zacatula en la costa, la provincia de Ávalos al sur de Jalisco, Colima, los límites con Ixtlahuaca en la provincia de Toluca, poblada principalmente por matlazincas y mazahuas, y alude a un empréstito que se pidió a los naturales a fin de solventar algunos gastos a favor de las autoridades españolas. ${ }^{17}$ Estos argumentos y testimonios pronunciados por don Antonio Huitziméngari en 1553 y don Constantino a finales del siglo XVI, que planteaban y resaltaban la colaboración de estos personajes y sus ejércitos de tarascos en la guerra chichimeca, fueron reproducidos pictográficamente en algunos códices coloniales elaborados por los pintores indígenas de diversas partes de Michoacán, buscando así la justificación de sus peticiones territoriales o reconocimientos de los linajes nobles ante las autoridades españolas. ${ }^{18}$

Ahora bien, con base en estos hechos de colaboración con los españoles y al mismo tiempo como resultado de una construcción ideológica claramente dirigida a justificar la conquista española y la imposición de la religión católica a los pueblos conquistados, encontramos al menos dos festividades fastuosas en las que se quiere dar muestras al conjunto de la sociedad de dichas colaboraciones y de las "bondades" de la cristianización de los indios conquistados. Una de ellas se da en la propia ciudad de Pátzcuaro y la otra en Guanajuato. La primera de ellas es la fiesta anual de San Pedro y San Pablo, celebrada en 1692, en una capilla edificada en la cima de una isla del lago de Pátzcuaro, en la que se celebraba el haberse "dado de paz el cazonci rey de Mechoacan" y haber abrazado la fe católica. Se festejaba así el haber derrotado a la idolatría, después de lo cual “...vaxaron a todos los naturales que estaban en los montes y cerros de esta comarca a las tierras de mi patrimonio y cacicazgo [don Pedro Cuiniarángari y don Antonio Huitziméngari]" ${ }^{19} \mathrm{Al}$ parecer la fiesta consis-

17 Ibídem; British and Foreign Bible Society, Ms. No. 374, London, United Kingdom.

18 Roskamp, Hans: La historiografía indígena de Michoacán; Paredes, Carlos, Roskamp, Hans y Sánchez, Gerardo: Guión museográfico. Exposición fotográfica de códices y lienzos de Michoacán, Manuscrito inédito, (1994).

19 Archivo General de la Nación, Tierras, 3127, expediente 1, foja 7. 
tía en trasladarse en canoas desde la ciudad de Pátzcuaro a la isla, con música e "invenciones", para festejar a San Pedro y San Pablo, patronos de la ciudad, en la que se convertía en la festividad más importante de Pátzcuaro. De esta manera, los hechos históricos, los dichos y el recordatorio anual en forma de fiesta colectiva, convalidaban y recordaban a las nuevas generaciones de los pueblos indígenas que eran fieles vasallos del rey y cristianos eternamente.

Otra celebración fastuosa realizada en Pátzcuaro con motivo de la asunción del nuevo rey de España, el borbón Felipe V, en 1701, nos mostraba justamente la imagen del cazonci en andas, "majestuoso y grave", seguido de cuatro cuadrillas de turcos con sus capitanes y, tras ellos, 400 indios de a caballo "que eran alguaciles, alcaldes y gobernadores de todos los pueblos sujetos a esta ciudad" y antecedidos por cuadrillas de indios "rayados en forma de chichimecas con arcos y flechas", es decir, estos últimos mostraban la imagen de los indios hostiles e insumisos a los españoles y esa fue también la imagen que se manifestó en pinturas y otras tradiciones que circulaban, incluyendo en la ciudad de México, que narraban el asedio y peligro que representaban esos indios "rayados" para las villas y ciudades de españoles. En contraposición a estos indios se mostraba precisamente al "Gran Cazonci" con todos sus súbditos, gobernadores y demás, aclamando al nuevo rey español. ${ }^{20}$

Con respecto a Guanajuato, se trata sin duda de una imagen construida a lo largo de los siglos, pero que tiene sus bases en hechos reales, justamente en la colaboración que los tarascos prestaron a los españoles en la conquista de la gran chichimeca, enclavada en el actual estado de Guanajuato, en el llamado Bajío. Sobre los chichimecas son múltiples las crónicas y testimonios que hay, todos dirigidos a resaltar su barbarismo, su apetito por asaltar, robar y matar a los viajeros; sus habilidades para cazar por medio del arco y la flecha y, en fin, sus hábitos de vivienda y formas de vida. Por otro lado, tenemos los hechos de conquista y la decidida participación que los ejércitos tarascos prestaron para la conquista de estos pueblos, no está por demás recordar que esta guerra duró prácticamente toda la segunda mitad del siglo XVI a costa de sangre y fuego, sacrificando múltiples vidas entre españoles, "indios amigos", religiosos y evidente-

20 Escobar Olmedo, Armando Mauricio, "Las fiestas de Pátzcuaro de 1701 por la aclamación del rey Felipe V" en, Tzintzun Revista de Estudios Históricos, Número 9, Morelia, enero-diciembre 1993, págs. 159-160; Pintura monumental conocida como “El traslado de las monjas", Museo Regional Michoacano, Morelia, Michoacán, México. 
mente sus aguerridos enemigos, entre los que se cuentan pames, guachichiles, tepehuanes, copuces, zacatecos y otros más, genéricamente llamados chichimecas por los españoles. ${ }^{21}$ De esta manera, la imagen que se fue formando y que está reflejada en la festividad que en seguida se trata fue la de los chichimecas como insumisos, bárbaros y asaltantes, mientras que por otro lado se muestra a los tarascos como amigos de los españoles, que acompañaron a los conquistadores y colonizaron estas tierras pobladas por estos pueblos hostiles, pero ricas en minerales de plata y oro, como Guanajuato mismo, Zacatecas, San Luis Potosí, Saltillo, etc.

La ceremonia que se realizó en la ciudad de Guanajuato fue con motivo de las fiestas de la jura de Don Luis Fernando, príncipe de Asturias, en el año de 1710. El testimonio es elocuente por sí solo:

"En el día 4 de este presente mes por la tarde se hizo un paseo a caballo por el gremio de los herreros vestidos de gala como que si va representado el monarca calsonsin que lo fue de los pueblos de Michoacán, siguiéndole un carro triunfal costosamente aderezado con un sitial en la cima y debajo de el sentado en una silla un niño ricamente vestido representando la persona de nuestro príncipe a cuyos pies en el descanso que hacían unas gradas, iba sentado Cristóbal Vicente indio principal ricamente vestido al modo de los indios mexicanos representando la persona del monarca Montezuma y a su lado la malinche vestida a dicha usanza mexicana y delante de dicho carro a pie otras muchas mujeres representando las cortesanas matronas de dicho monarca Montezuma..... ${ }^{22}$

\section{Conclusiones}

A través de estas páginas se ha abordado, de forma general, el tema de la subsistencia de un poder político heredero de la época prehispánica, bajo el nuevo régimen colonial establecido por la Corona española y administrado en forma directa por los conquistadores, colonizadores y primeras autoridades representantes del rey en tierras americanas. Se ha estudiado básicamente el XVI, precisamente el siglo del contacto y de los primeros encuentros, no siempre amistosos, entre ambas culturas y que para el caso

21 Ciudad Real, Antonio de: Tratado curioso y docto de las grandezas de la Nueva España, García Quintana, Josefina y Castillo Farreras, Víctor (edición), volumen II, Universidad Nacional Autónoma de México, México, 1993, págs. 159-162; Powell, Philip W.: La guerra chichimeca (15501600), Fondo de Cultura Económica, México, 1977.

22 Archivo General del Estado de Guanajuato, Colección Agustín Lanuza Dresdier, sección festividades, serie 12.1.4 (personajes), f. 13-19. 
de Michoacán es un momento de grandes cambios y transformaciones en todos los ámbitos de la sociedad autóctona, sobre todo durante sus primeras décadas. La introducción de las instituciones de Gobierno en los pueblos de indios en este caso está muy relacionada con el establecimiento de la institución del hospital y los ideales programáticos del obispo Vasco de Quiroga, de manera que se trata de un personaje imprescindible para la comprensión de la historia de los pueblos tarascos de la época colonial.

La historia de estos pueblos no estuvo desde luego exenta de conflictos y dificultades inherentes al proceso de conquista y sometimiento a través de la cruz y la espada que caracterizó esta etapa en la historia de Michoacán, por lo cual la antigua nobleza uacusecha colaboró con los conquistadores y a partir de ello hizo valer sus derechos y privilegios, así como paralelamente surgieron nuevos grupos de poder en un escenario político totalmente atomizado, contrario a la forma en que prevalecía en la época prehispánica. Nuevos actores políticos para los cuales surgieron también nuevos conflictos y nuevas formas de enfrentarlos, bajo la nueva legislación española y "novohispana", caracterizada por la casuística y por la búsqueda de soluciones inmediatas.

La institución del Cabildo indígena y la del hospital están también estrechamente relacionadas, constituyéndose en torno a éstos el centro neurálgico del quehacer político y social de los pueblos de indios y el punto de cohesión que perduró a través de los siglos. Son parte importante no sólo en relación a los aspectos políticos, económicos y sociales, sino que también están presentes en la traza y forma de los asentamientos de estos pueblos desde el siglo XVI.

La memoria histórica de los pueblos tarascos y de otros más que poblaron antiguamente las tierras de Michoacán, está impregnada de varias tradiciones basadas en los hechos narrados brevemente en estas páginas, no sólo en la actualidad, sino también, como se ha visto, en distintos momentos de su historia, en su memoria colectiva. 